\title{
The EAP competencies in a group case study project as revealed by a task-based analysis
}

\section{Introduction}

International students in EAP programmes in the UK need to be able to cope with real academic assignments which reflect "...the cognitive, social and linguistic demands of specific academic disciplines" (Hyland and Hamp-Lyons, 2002, p. 2). Although individual assignments remain widespread, assessed group project assignments are becoming increasingly popular across a diverse range of disciplines and programmes at the University of xxxx according to a university-wide needs assessment (Thondhlana \& Gao, 2009). Similar developments have been noted elsewhere (e.g. Ashraf, 2004; Chapman et al., 2006; Hansen, 2006; Victoria University of Wellington, 2004; Evans and Morrison, 2011). EAP practitioners need to consider whether they are adequately preparing and supporting international students to perform effectively within group projects in their academic departments and on into their future employment.

This current study investigates the task demands of an assessed group case study project in the first term, first year, undergraduate module 'Computers in Business' in the School of Business. It was selected as a follow up to the university-wide needs assessment (Thondhlana \& Gao, 2009) and because international students who had recently completed a pre-tertiary Foundation Certificate Programme at the $x x x x$ and entered the School of Business identified it as particularly challenging. Despite the fact that the Foundation Certificate develops group work skills and includes assessed team projects, this project, they said, was longer and much more complex. The project is intended to prepare international and home students not only for the challenging group tasks used in university assessments but also for 'real world' assessment centres where students compete for summer placements or third year internships and later for jobs in the business world. Findings from the study have provided new insights into the expectations and competencies needed for group projects which, in turn, have guided adjustments to the team projects in the Foundation Certificate Programme and presessional programme.

As task based syllabuses are common in EAP in the UK, this study analysed the case study project using a task based framework (Thondhlana \& Smith, 2013). Most EAP practitioners will be familiar with tasks as goal directed activities involving collaborative interaction as in real world communication (Crookes, 1986; Bygate et al., 2001; Ellis, 2003; Mohan and Smith, 1992; Skehan, 1998; Van den Branden, 2006). Skehan (1998, p. 95) states that in tasks, "meaning is primary; there is some communication problem to solve; there is some sort of relationship to comparable real world activities; task completion has some priority; (and) the assessment of the task is in terms of outcomes." Long and Crookes (1992) distinguish between 'real world tasks' and 'pedagogic tasks' with the former being what the students will do eventually with language (e.g. academic study or work) and 'pedagogic tasks' being used in the EAP classroom. In task-based syllabus design, 'pedagogic tasks' are designed in such a way as to approximate the real-world target tasks in terms of content, steps the learners have to take, the options they choose from, language aspects and so on. 
Research findings on the specificity of tasks, genres and discourse practices can benefit both subject specific and common-core approaches to EAP (Dudley-Evans and St John, 1998; Flowerdew and Peacock, 2001; Hyland, 2002; 2006; 2008; Johns, 1988). However, Johns (1988) argues that the specific skills and conventions needed in academia may be greater than the similarities and students have to readjust to each academic discipline they encounter. Hyland (2002, p. 393) maintains that 'scholarly discourse is not uniform and monolithic' but constitutes a variety of subject-specific literacies. Studies such as this one can reveal more about the authentic tasks and specific linguistic requirements needed in discipline specific modules and thus assist EAP programmes to become more effective.

An initial investigation subdivided the group case study project into a number of connected tasks. The selection, organisation, grading and sequencing of tasks within the project form a 'task chain', or a series of 'facilitating tasks' that relate to, or build on, each other leading to a final assessed group report and presentation. Long and Crookes (1992) advocate breaking up a project into sub tasks to replicate real-world tasks and such 'task chains' are often identified as challenging (Ellis, 2003; Willis and Willis, 2007).

Case studies are a popular learning mode promoted by many professional schools, such as the School of Business, as they explore a genuine situation with all the twists and turns of authentic life (Watson Todd, 2003). As a teaching method, they make connections between theory and applied practice and encourage reflection and analysis of authentic real world dilemmas by providing a window into professional development. Cases are frequently designed to promote group collaboration through the sharing of experience, ideas and varying perspectives. Through this exchange of opinions, students learn to respect differing opinions and may rethink and even restructure their own point of view. In addition, face-to-face interpersonal skills require students to listen actively, elicit and spontaneously question others, and clarify and justify opinions on the spot which can be very challenging for international students (Jackson, 2002; 2003; Smith, 2009).

This exploration of the task demands of the 'Computers in Business' assessed group case study project aims to increase EAP practitioners further understanding of the competencies necessary for the real-world assessments faced by undergraduate students in their academic study. It also aims to demonstrate the complexity of group case study projects and offer insights into the challenges which students need to be prepared to face in their academic studies. The EAP skills requirements identified by this investigation will be compared to The BALEAP Can Do Framework of Competency Statements for International Students (Masters Level) which are also subdivided into skills. This was created by interviewing lecturers from various UK universities involved in a range of disciplines (BALEAP, 2015).

The purpose of the original investigation was to explore the project brief in order to reveal the chain of tasks and then analyse each task in terms of task type and task complexity. This paper investigates the demands of each task in order to reveal the EAP skills and academic competencies international students require for the project. The analysis draws on interviews with the module lecturer who leads 
a team of lecturers working on the module as well as other documentation such as coursework feedback, marking notes and the Undergraduate Student Handbook. As a result of this somewhat limited exploration, recommendations will be made in terms of language skills, group work competencies and academic proficiencies necessary for successful completion of the component tasks and the assessment.

\section{Data and method of analysis}

Firstly, the case study project document from the undergraduate 'Computers in Business' module was examined. This document instructs student groups to prepare a design bid for an exhibition with online promotional support. It focuses on Reduce $I T$, a government-sponsored project to help small and medium sized enterprises to reduce their environmental impact through improved computing. Assessment for the module consists of a 4000-5000 word report and a 10 minute presentation which combine to provide $60 \%$ of the module assessment. The project aims to develop an array of competencies including information communications technology; specification; budgeting; strategy formulation; group working; collaborative document preparation and presentation skills (Module guide, 2008/9). Approximately 650 students, both home and international, are enrolled annually on the module and although the format of the case study remains much the same each year, the content is substituted.

Investigation of the project document identified nine constituent tasks which were then analysed in terms of two criteria: Task type and Task complexity. Task type includes the nature of the task in terms of design features (e.g. format and content) and interactivity as certain task features generate more interaction than others (Duff, 1986; Ellis, 2006; Garcia Mayo, 2007; Long, 1989; Pica and Doughty, 1985; Skehan, 1998). The interactive variables investigated included flexibility of the tasks, the extent to which a task required definite answers and solutions, interpretation, and information exchange or negotiation leading to agreement. There may be some overlap between interactive variables in places; for example, closed tasks which require a definite answer or solution are more interactive as are convergent tasks which require the group to agree on a shared solution (see Thondhlana \& Smith, 2013 for a more detailed account).

Task complexity refers to nature of the input, the task conditions, the operational processes and the required outcome that are inherent in the task (Ellis, 2003; Robinson, 2001). These information processing demands result according to Robinson (2001) from the design characteristics of the task which can be manipulated by the task designer. 'Task complexity' was subdivided into three criteria for analysis: 'cognitive complexity' of the input document and instructions; 'code complexity' which refers to the linguistic features and 'communicative stress' experienced by learners. Other studies (Brindley, 1987; Candlin, 1987; Foster and Skehan, 1996; Garcia Mayo, 2007; Prabhu, 1987; Robinson, Ting and Urwin, 1996; Robinson 2006; Skehan, 1998), coupled with insights from the lecturer and the researchers' perceptions of the nature of the academic group tasks all contributed to this framework (See Thondhlana \& Smith, 2013 for further details). 
Cognitive complexity was analysed according to eight sub criteria. These are:

propositional density (e.g. single spacing, range of information and length, complexity of vocabulary and syntax);

input format (e.g. oral, written or pictorial input) demands;

degree of structure (e.g. whether clearly structured or freeform);

complexity of instructions (e.g. number of specific, general or limited elements,);

clarity of input (e.g. sufficiency, density, structure);

information type (e.g. research material, task brief);

task sequencing (e.g. requiring one or multiple things to be done simultaneously) and, lastly, input familiarity.

Code complexity was analysed in terms of syntactic or grammatical complexity and lexical complexity which forms the basis of most readability formulas (Crossley, Greenfield and McNamara, 2008).

Syntactic complexity refers to the complexity of sentence structure; a wide variety of both basic and sophisticated structures are usually available in any given text. In this study, T-unit (minimal terminable unit) analysis, proposed by Hunt (1970), was used to analyse the syntactic complexity of the project document because it has been found to provide an objective and reliable method of determining the overall complexity of language texts. A T-unit is the shortest unit which can be taken from a piece of discourse. It consists of a main clause plus any attached or embedded subordinate clause. This research calculated the average length of a structure, or T-unit length (words per T-unit) and complexity ratio (number of clauses per T-unit as a measure of subordination). T-units were identified and the number of words per T-unit were counted and checked. The syntactic complexity was then examined by two researchers who calculated the average number of words per T-unit in each section.

Lexical complexity refers to complexity of the technical and sub technical vocabulary used in the task brief. VocabProfile (Compleat Lexical Tutor) was used to provide a lexical text analysis. It identifies the type of words in the document in terms of frequency, detecting "the most frequent 1000 word families" as well as the second most frequent 1000, the Academic Word List (AWL) and other words (Compleat Lexical Tutor). The first 1000 word families are divided into content and function words and consist of the root family, types and tokens; these account for $72 \%$ of general frequency, and, together with the second 1,000 word families, account for $79.7 \%$ of frequency. This provides a suitable goal for initial second language learning (Nation and Waring, 1997). The AWL, developed by Avril Coxhead, identifies 570 words commonly found in academic texts; for an academic document, Coxhead and Nation (2001) show that the percentage of vocabulary from the AWL is generally $8.5 \%$. In addition, a readability score (Child, 2010) was used to indicate the reading level and the grade level of the project brief. A concordancer (Compleat Lexical Tutor) was used to identify the frequency of key words, such as group or exhibition in the project document. This was also checked by two researchers. 
Finally, communicative stress is the level of stress learners are expected to experience when performing tasks of diverse degrees of complexity (Candlin, 1987). Skehan (1998, p. 88) sees it as '...the performance conditions for accomplishing a task'. A number of performance conditions were identified as analytical variables in this study (Anderson and Lynch, 1987; Brown, 1984; Candlin, 1987; Foster and Skehan, 1996; Robinson, Ting and Urwin, 1996; Skehan, 1992; 1996) These comprised of: the time limits available for the task; the number of steps or elements required or involved; the sequence of operations; the sequence of information presentation (e.g. to what extent the task follows a clearly structured organisation) and the extent to which participants are familiar with aspects of the task.

This current investigation explores the demands of the component tasks on the students, especially international students. Two interviews were conducted with the senior business module lecturer - who was already familiar with the Foundation Certificate Programme (having visited classes to outline the degree offerings available at the School of Business) and the presessional 5-week business course. The dense six-page case study project brief, coursework feedback and marking notes were also scrutinised as well as two recommended readings and the Undergraduate Student Handbook.

The demands of the project for international students were analysed using a number of factors that influence difficulty. These include learner factors (e.g. language level and research skills); application of concepts; personal affective response (e.g. confidence and motivation); other skills (e.g. time management and IT skills) and familiarity with the topic content, the task design, the academic conventions and group dynamics. In addition, the support made available to the students was taken into account. In this study, these features will be considered through the senior module lecturer's perspective of students' abilities, their skills and their affective responses and through evidence from other documentation. In the interviews, the business lecturer was asked about what tasks students found difficult and the support available. This clarified a number of issues relating to task complexity, group work performance and difficulties faced by international undergraduate students. The criteria for task demands (see Table 1) were adapted from task based teaching (Candlin, 1987; Nunan, 1991; Prabhu, 1987; Robinson, 2006; Skehan and Foster, 1997) and the observations of the lecturer. Ellis (2003, p. 223) notes that, “'familiarity of information' relates to 'task difficulty' as much as to 'task complexity' as it concerns the relationship between the theme of the task and the individual learner's world knowledge."

\section{Table 1}

The project document mimics the style of documents written for business consultants or an assessment centre. The first part provides general information and project instructions in seven short sections. The second part, entitled 'Your Project Brief - Reduce IT!' outlines the expectations of the IT project and provides information on the assessment in four sections. Each section has a short bold heading but some tasks are not obviously marked. 
Support for the students is provided in a variety of ways. The weekly lectures give background theory and advice: for example, on minute writing skills. Each project is supervised by one of the lecturers in the team and the department has an open appointment system so students can meet with lecturers as needed. The Case Study Review (CSR) meeting requires the group to meet and discuss progress with their lecturer. In addition, the Undergraduate Student Handbook offers advice and project workshops are offered by a skills development officer who offers six sessions. The first is required for all students whereas the other five are optional. International students can also access in-sessional support via one-to-one or group meetings.

Task analysis of the project brief identified nine individual tasks (see Table 2 below). These were checked with the business lecturer and a senior EAP lecturer. They were then classified into EAP competencies: reading and research (Tasks 1, 3 and 5); group formation and interaction (Tasks 2 and 4); exhibition design and planning (Task 6); final report and presentation assessment (Tasks 7 and 9); and allocation of marks (Task 8). They were initially analysed using the Task type and Task complexity criteria and most recently using the Task demands criteria outlined above.

\section{Table 2}

\section{Findings}

\subsection{Reading and Research (Tasks 1, 3 and 5)}

Reading the project document (Task 1). The six-page project document consists of a loosely organised (freeform) brief that is dense, single spaced, and has little obvious structure and only one diagram illustrating the exhibition layout. It is also static in that it remains the same during the project. Because of the multiple tasks involved, the brief has to be consulted right through the project to identify and clarify the specific requirements of each task. In terms of task type, interactivity when reading the brief is divergent but tight, closed and interpretive.

An analysis of task complexity of the document reveals the reading task to be cognitively complex. The linguistic complexity also presupposes a high level of language proficiency including knowledge of technical discipline specific language, the AWL and general functional language as well as the language of group assignments. Furthermore, some familiarity with green computing content, interactive exhibitions, and the academic expectations of group work is also needed. Consequently, the potential for communicative stress from the reading of this task is significant, according to the lecturer.

A detailed exploration of the code complexity of the document language revealed the use of long complex sentences with some repetition and redundancy typical of real world business case studies and higher than expected levels of academic vocabulary. The syntactic T-unit analysis (Hunt 1970), revealed that the document has a high level of syntactic complexity with the average syntactic unit in 
the brief being 27.2 words long, with the shortest 10 words and the longest 67 words. The vocabulary profile analysis of the brief showed a significant proportion of words in the document $(75-80 \%)$ came from the first 1,000 word families in English and a very low proportion (3-4\%) from the second 1,000 word families. This is somewhat different to the 70-10-10-10 expected from a typical document (Cobb n.d.). The level of vocabulary from the AWL, furthermore, was somewhat above the $8.5 \%$ average provided by Coxhead and Nation (2001) with Part 1 at 10.37\% (example in Appendix) being somewhat lower than Part 2 at 13.62\% (Thondhlana \& Smith, 2013). The readability measure (Child, 2010), averaged over Flesch-Kincaid, Gunning-Fog, Coleman-Liau, SMOG and Automated readability showed the document to have an average grade level of 12 (USA). The Gunning-Fog measured the grade as 13.7 whereas SMOG measured it as only 10.4 .

There was a certain amount of predictability in the language of the project document according to a concordancer (Compleat Lexical Tutor). In the task instructions, the frequent use of three modals, 'should', 'will' and 'must', highlight required elements of the tasks along with the use of 'should not' to indicate what to avoid. The term 'group' appeared more than 50 times and collocations relating to 'group member/s' were also used quite frequently to explain the group tasks in the project document. Surprisingly, language relating to the students' need to collaborate, negotiate and agree while doing the tasks was much less frequent. Other terms relating to the required project components revealed the use of various forms and collocations of the words 'presentation', 'exhibition' and 'minutes' (Thondhlana \& Smith, 2013).

In this case, communicative stress was caused by the complexity of the project document, the use of a case study format and the real world expectations of the project. This was deduced from the results of the project brief analysis which shows the number of steps involved in the project, the syntactic difficulty, and the lexical complexity. Other factors mentioned by the lecturer include time constraints and a new British university environment. Initially, the urgent need to identify the steps in the task sequence and then participate in discussion of the document also created stress.

Task Demands The lecturer acknowledged that in spite of the support available for international students, reading the project brief is 'quite challenging.' Many students 'flip through it' or read the section on assessment but they need to read it all carefully in order to grasp the overall picture as well as the specific instructions and required processes. Other learner factors included poor reading skills, especially for mining the brief to identify the various components and requirements in the text. In terms of language, the lecturer indicated that international students often needed better cognitive strategies to process the language and more advanced subject specific language.

Familiarity with a case study approach is essential for the project as students need a deep comprehension the project brief in order to understand the development sequence of the case and identify assessment requirements and deadlines. Researching Reduce IT (Tasks 3 and 5) also requires some familiarity with green computing content and interactive exhibitions in a UK context. According to the lecturer, some students lacked higher order critical thinking skills involving analysis, 
interpretation, inference and meta-cognition as in some places the document could be open to a variety of interpretations. In other places students were expected to select and evaluate between relevant and irrelevant information:

You should also be aware that sometimes you might be given material in the case which is not relevant to the task which you have been set. Here, you will have to trust your judgement and ignore it; the inclusion of irrelevant material in your analysis may be penalised.

(Undergraduate Student Handbook, p. 41)

All of these demands create enormous challenges in terms of EAP reading strategies as students need advanced skills for mining texts and identifying key information. In addition, they need to deal with long and frequently complex sentence structures as well as complicated instructions requiring interpretation. In terms of language, adequate AWL vocabulary as well as subject specific language for green computing and exhibitions is necessary.

Researching Reduce IT (Tasks 3 and 5). Two web documents on green computing are recommended as initial background sources to research ways to reduce environmental impact through improved computing. In terms of task type, these two readings are highly complex as students need to develop familiarity with report documents and the concept of green computing. Intel (2007) is a clearly structured, 8-page report document which includes a table of contents, an executive summary, and bold subheadings in a 2-column format along with 2 graphs and a chart. The second, ETNO and WWW (2006) is a 44-page report document with several full-page colour pictures and various graphs and charts in a 2-column format. In the same way, the group must then identify and read additional literature on green computing. Thus the research task requires both individual research and collaborative effort to converge information.

Overall, this research task is cognitively highly complex as students need to read the two dense, lengthy academic recommended sources, according to the marking notes. An investigation of the two sources revealed that the propositional, syntactic density of the two recommended readings was somewhat easier than the project brief as revealed by a T-unit analysis. It exposed the code complexity of the Intel (2007) sample to be 22.3 and the ETNO and WWW (2006) report to be 19.2 as compared to the project brief with an average syntactic unit of 27.2. The lexical complexity in these academic texts also make this reading task arduous. For example, the level of vocabulary from the AWL was above the $8.5 \%$ average provided by Coxhead and Nation (2001) in all three documents with Intel (2007) being the highest at 14.36 and the ETNO and WWW (2006) report also being higher than the project brief at $13.48 \%$ (Part 1 at $10.37 \%$ and Part 2 higher at $13.62 \%$ ).

Task Demands For this research task, the lecturer noted that all group members needed effective research skills to identify appropriate sources and critical reading skills to find and process the required information. In addition, the group must translate the dense written text into spoken language in order to explain it to each other and agree on the interpretation and synthesis of the information for the exhibition and report. He stressed the importance of finding relevant information noting that 
effective discussion requires informed participants. Good projects focused on green computing but some projects lacked any reading on the concept. Although lectures on green computing were offered and guidelines provided, students, as noted by the lecturer, tended not to read the brief carefully and, as a result, some even missed or ignored the crucial information about the two recommended sources. Others failed to follow an idea through and actually build it into an argument.

Practical research skills were also a challenge for some students. This was a key issue according to the lecturer who had initially tended to assume that students could use the web and do research. Some simply could not find things on Google and in a key word search seemed unable to produce additional key search terms. Others were limited by using the Windows operating system and Google for searching when it was necessary to be able to use a variety of search engines. The lecturer also highlighted a lack of familiarity with the school's online learning pages.

A lack of familiarity with the discourse genre, content and cultural expectations of concepts, such as 'exhibition' and 'green computing', can also result in immense communicative pressure especially for international students. Another issue was time management which, in some cases, led to rushed research and was a general indication of the inability to organise the research component effectively. This was despite advice in the Undergraduate Student Handbook on deadlines and how to organise time. "Most group projects will have very strict deadlines, and so it can be very helpful to set reasonable time limits for each proposed stage of the project" (Undergraduate Student Handbook, p. 47).

\subsection{Group formation and organisation (Tasks 2 and 4)}

These tasks require students to create formal learning groups of five to seven students, select a group leader responsible for coordinating group project activities and an administrator responsible for preparing minutes which record the effectiveness of the group. After reading the project brief individually, the group would need to negotiate and collaboratively agree on a single interpretation of the steps and the requirements. Then they "brainstorm and generate ideas about how best to tackle the project" (Undergraduate Student Handbook, p. 47) allocate tasks and work together to assist each other. Next they prepare a Group Status Report (GSR) report in time for the Case Study Report (CSR) meeting.

Furthermore, group discussion is challenging in a larger learning group. Students must listen carefully, share opinions, make judgements, negotiate and agree on meeting times and places, allocation of research tasks and preparation of their CSR report. These task types are highly interactive and require close collaboration; the tasks are tight, closed, interpretative and convergent requiring members to negotiate and reach agreement on work allocation and deadlines; to pass minutes as a correct record and to plan the report. At the CSR review meeting, the first set of minutes and the report, which has to include the names of group roles, the actions taken and the problems faced, are due. These activities require independent student-centred learning as the groups must take responsibility and act autonomously. 
The group management is cognitively complex as the group would need to understand the academic expectations of group processes and build relationships with other participants. The complexity originates from the multiplicity of tasks needing to be identified, understood, negotiated, and allocated to individuals as well as the systematic minuting on a group designed form. They need to identify and individually research additional academic literature on green computing and later reconvene to share, negotiate, synthesise and reach agreement on the interpretation of the information. This collaborative effort to disclose and then merge information makes the task challenging as it requires fluent and proficient discussion skills (code complexity).

Group formation and organisation tasks could cause considerable communicative stress as lack of familiarity with various task aspects (including group processes, conventions, dynamics and cultural expectations) is a major factor. Overseeing meeting schedules, deadlines and group negotiations which require consensus, such as those surrounding the exhibition specifics, would also be stressful.

Task Demands The lecturer noted that international students in particular found the group tasks demanding and challenging. They often had difficulty approaching other students to form a group, partly because of lack of familiarity with the class and module expectations and partly because of lack of experience with group work processes. The lecturer noted that the groups formed are increasingly multicultural which creates its own communication challenges and there were often difficulties in allocating work and setting deadlines. Many groups were generally found to lack the ability to take responsibility and manage the project effectively despite support provided. Minute taking proved to be testing, despite information provided in the lectures giving specific guidelines, and although they divided up the work, they often failed to utilise members' strengths. It was observed that many found interaction language challenging, especially international students who were not familiar with the UK experience, so discussion, collaboration and especially resolving disputes, which is critical in group work, was challenging.

International students need mastery of a full range of communicative competences for group participation. Communicative competence is generally recognised as the skills and capabilities to meet the demands of a communicative event. It includes linguistic, sociolinguistic, strategic and discourse competences (Canale and Swain, 1980). However Celce-Murcia, Dörnyei, and Thurrell (1995) centre their model in discourse competence, which seems more appropriate for EAP, and highlight the significance of sociocultural competence and strategic competence (see Figure 1 below). They identify sociocultural competence as necessary because it relates to "the speaker's knowledge of how to express messages appropriately within the overall social and cultural context of communication, in accordance with the pragmatic factors related to variation in language use" (p. 23). They also give a fundamental role to strategic competence with its core of communication strategies for achievement and repair and a variety of interactional strategies. Thus intercultural communication skills would be necessary for the interactive tasks. Interaction competence is closely linked to both speech acts, such as exchanging information, complaining or expressing opinions, and fixed formulaic 
language patterns or functions "in conveying and understanding communicative intent" (p.17). More recently, Young (2009, p. 11) has identified resources which relate to interaction: 1) identity resources including the identity and status of the participants; 2) linguistic resources including register and modes of meaning and 3) interactional resources including speech acts, turn taking, repair and boundaries. Finkbeiner (2008, p. 131) stresses that "In our globalising world, we cannot just glance at the surface and assume we understand others. We need to dive deep not only to understand others but also ourselves" and develop cultural competence. Such interactive competence or social interaction in context, as with the collaborative co-construction of meaning, can be demanding for international students.

\section{Fig. 1.}

International students also need to have mastered a range of communicative skills in order to effectively communicate in these multi-cultural group interactions. "... The ability to effectively and appropriately execute communication behaviours that negotiate each other's cultural identity or identities in a culturally diverse environment" (Chen and Starosta, 1998, p. 231) is critical for successful group interaction in this context.

\subsection{Plan exhibition (Task 6)}

The next project task requires the design and planning of the Reduce /Texhibition. After gathering information on exhibitions in general, the group must agree on a design for an interactive Reduce IT exhibition. The specific guidelines in the brief require three zones to be included: The Energy Reduction Zone; The Resource Reduction Zone and The Travel Reduction Zone. In terms of interactivity, the exhibition design task may be described as tight, closed, interpretive, convergent, requiring 2-way information exchange and extensive negotiation because the group has to agree on a range of specific components and design features.

In addition, the task involves the synthesis of instructions from different sections of the brief and assumes familiarity with exhibitions. This includes space and exhibit design, planning the work for two staff and explaining the exhibition in an appropriate brochure genre for the typical visitor. The code complexity of the project brief, as mentioned previously, provides complex instructions on the various features of the exhibition. Additionally, the design, writing and promotion of the exhibition through the brochure and the web site necessitate the use of detailed explanation and persuasive marketing language. Preparing the overall exhibition is stressful as time is limited and sequences must be followed. Altogether, this is a highly complex task.

Task Demands The marking notes confirmed the high level of complexity of this task which demands creativity. The lecturer acknowledged the task presumes some familiarity with the concept of 'exhibition' and introduces various challenges including dealing with diverse simultaneous 
components. These include applying green computing knowledge; creating diagrams and other visuals; inventing hands-on interactive exhibits and developing a promotional visitors' guide in an appropriately engaging style. Lack of work experience, exhibition know-how and budgeting knowledge was a significant drawback for some international students when identifying a specific job description for the two IT staff. Being precise in academic writing was identified as another issue as students were often too descriptive and needed to specify a particular product with a real price from a named supplier. Other challenges included the need to address ethical issues and to possess high level IT skills to create online software materials quickly. When applying concepts, the best, most creative groups produced models, videos, posters and handouts.

\subsection{Final assessment: Plan and write report; prepare presentation (Tasks 7 and 9)}

Finally, the assessed group task includes both the preparation of a 5,000 word report and the design of a subsequent 8-10 minute oral presentation. The report writing strategy involves collaborative planning as the 7- section report must include the minutes, the elements of the exhibition website, details of the exhibits and the guide. Ede and Lunsford (1990, p. 74) define a collaborative writing strategy as the plan that a writing group will use to write collaboratively or in Lowry et al.'s (2004, p. 13) terms, it is "... a team's overall approach for coordinating the writing of a collaborative document." This writing task is tight, both closed and open, interpretative, convergent and requires extensive negotiation.

As with previous tasks, the cognitive complexity of the task is in planning, understanding and interpreting the instructions, and sequencing the information in the report following the precise instructions. The report structure includes an executive summary followed by seven sections, a reference section and an appendix consisting of four sets of minutes. The code complexity of the instructions is demanding as each section begins with the instruction "This section should..." and states the expectations for the input. For the group, following such detailed instructions, agreeing on a shared interpretation, planning the report sections so one section does not dominate, writing, editing, referencing and proofreading to adhere to the deadline creates communicative stress. In addition to this, penalties for plagiarism are severe and if the group fails to follow Harvard Style referencing or include an appendix with minutes then the project mark immediately drops. The report is due the day of the presentation.

The final task type involves planning and presenting a portion of the written report as an 8-10 minute oral report. The group must agree on presenters, content, slides and other visuals. While initially this task is open and divergent, and thus less interactive, it involves a tight, interpretive, convergent, twoway, optional information exchange. As with previous tasks, the cognitive complexity of the planning of the presentation is caused by understanding and interpreting the instructions in this crucial final step as well as negotiating to develop a successful presentation. Such preparation would require extensive negotiation and therefore considerable interactivity. For example, the group needs to select 
presentation content from the CS Report following the instructions and using language to effectively persuade, highlight and justify.

In terms of cognitive code, the group must use persuasive language to convince the Project board to select their bid over others. The instructions are again quite complicated and require interpretation. "The objective of this presentation is to convince the Project Board why they should select your bid above all others. What you include in the presentation is therefore up to you. However, you are advised that it would be sensible to selectively highlight the key features of your exhibition, website and Web 2.0 strategy and to justify your overall expenditure. You are also advised that trying to cover your whole report within your presentation is almost certainly a very bad idea. The presentation of excessive purchase details is also unlikely to be warranted. Indeed in general, less is likely to be more" (Authors' italics). The collaborative planning of the presentation for the same deadline as the project report creates communicative stress. Structuring the presentation following the necessary steps in the time available and ensuring slides, visuals, videos or models follow academic expectations are challenging.

Task Demands Misunderstanding the written report guidelines and the need to balance the required report sections often led to one section dominating the submitted report. In addition, failure to produce the executive summary as a concise summary emphasising the key elements of the report and omission of key elements, such as reference to green computing, also occurred, according to the marking notes. Some groups seemed to see written texts as sacred and did not want to change their sections to fit the report requirements or wanted each section to have an equal number of words rather than varying section size according to the needs of the content and argument. Often they needed to backtrack and seriously reorganise the materials. Other groups seem to require each group member to submit an equal number of words although other contributions, such as the skills of a group leader or IT specialist, can give equal input but not in terms of words.

According to the feedback, some groups neglected to follow the required Harvard Referencing System, despite the fact that the Undergraduate Student Handbook clearly states that poor referencing will affect marks. Other groups failed to adhere to the required deadlines finding the time management of such a full term project too difficult to manage. These challenges generally follow from the complexity of the project document.

The planning for the presentation includes not only the production of slides and accompanying visuals, but also the need to emphasise the main features of the exhibition, highlight the website and Web 2.0 strategy and justify any expenditures. As the instructions note that "less is likely to be more," the group needs to be both precise and concise with their coverage of the report. The need to be familiar with academic presentations and to rehearse to ensure timing can put immense pressure on the group. However, the lecturer noted that not all group members must be involved in the presentation and as a result the native speakers are frequently selected as non-native speakers often lack confidence. 


\subsection{Task 8: Allocate marks}

This task of allocating marks appears more straight forward in theory than it is in practice as members have to negotiate and agree on marks based on each individual's contribution. The group's minutes document these contributions so the negotiations, and therefore interactivity, are dependent on whether problems regarding individual contributions are noted when minutes are passed as a correct record of the meeting. If no problems are noted, members received the same mark but if contributions are unequal, agreement would need to be reached on exactly how marks would vary. The complexity of this task arises from understanding the instructions and following the guidelines precisely. Depending on complexity of the group dynamics, the process of agreeing on and allocating marks before the final deadline may be stress free or extremely stressful.

Task Demands In interview, the lecturer confirmed that demands of this task are dependent on the group experience. If members participate equally, and the minutes record this, then no difficulties are experienced. However in some groups, especially where the groups have serious difficulties with members who lack motivation, difficulties can occur with marks allocation and it may be difficult when marking to ascertain who has done what. Students who fail to attend meetings and participate are identified through the minutes and the group then assigns an unequal mark. However, sometimes groups have difficulty facing up to the issues or agreeing on the allocation of marks and as a result give equal marks for unequal contributions. The lecturer also noted that occasionally groups "explode" and expel members so the detail of such events needs to recorded and justified in the minutes.

\section{Discussion}

This investigation of a group case study project in business has revealed a complex combination of linked or chained tasks leading to the final assessed report and presentation. The project document outlining the tasks was found to be dense and complex with quite precise instructions about what groups 'should' or 'should not' do. It is clearly extremely challenging for newly enrolled international undergraduate students, and although support mechanisms are provided via lectures and the lecturers, they do not always access them. This issue was discussed with the lecturer who stated that the project brief was deliberately designed to be realistic and challenging so first year students would be motivated to understand the demands made by assessment centres and rise to the challenge. Colbeck, Campbell and Bjorklund's (2000, p. 70) study of university undergraduate engineering programs in the USA found that "students liked working on 'real world projects'... problems faced by industry that had many possible solutions, and where the focus was more on the problem solving process than on calculating a predetermined right answer."

The project is designed to use 'formal' learning groups of 5-7 students who work together throughout the term to complete the tasks leading to the assessment (Davies, 2009). Leki (2007) stresses the importance of international undergraduates being communicatively competent to work effectively in teams, but states they often lack experience of working in larger learning groups which can require a wider range of language skills, fluency and interactional competency to engage in group discussions. 
They also have to collaborate in order to agree on issues and critically analyse and apply concepts from lectures and research.

Effective group organisation demands a range of 'other skills' as the tasks mirror real world tasks used in assessment centres. Analysis of the project brief revealed the need for group management in order to set goals, plan tasks, allocate group work, monitor progress and develop IT expertise, which Watson Todd (2003) includes as global practice in EAP. However, within the group, individuals are required not only to interact and collaborate but also to be autonomous, responsible and able to manage time and deadlines. This may be especially challenging for international students who have experienced a more traditional teacher centred education system and who lack confidence in moving towards autonomy (Jackson, 2003). The lecturer observed that although the introductory lecture and Undergraduate Student Handbook advise students on team work processes and time management, students often lacked the required organisational skills necessary for the group to engage and be successful. In addition, IT and other work was often not allocated according to individual strengths. These are quite consistent with the typical difficulties found with group projects which include scheduling conflicts, lack of leadership, difficulties with group dynamics and students lacking confidence or motivation, organisation skills, or preferring to work alone (Chapman et al., 2006; Hansen, 2006; Davies, 2009).

The business lecturer also noted that some students, particularly international students, found it difficult to approach other students to form a group as they were allowed to self select groups. This was often ascribed by the lecturer as due to lack of familiarity with other students, lack of confidence or limited experience with team work processes (personal affective response). However, allowing students to self-select groups does not necessarily create a good mix of skills and experiences; nor does it ensure the mixing of international and home students. Leki's study (2001) noticed that team work was not popular with international students due to difficult relationships with local students and because they tended to be assigned subordinate roles in the group activities. Shepperd (2011) emphasised that appropriate team formation was essential in an undergraduate group project to ensure all groups use English and international groups build intercultural communication. Summers and Volet (2008) agree that intervention may be necessary to ensure local students work with international students. However, despite the fact that students often think otherwise, they indicate culturally diverse groups often perform better together but Davies (2009) is less convinced.

In addition, research has shown that groups do not just form but that they go through a complex process involving 'forming' (acceptance seeking), 'storming' (establishment of task rules, roles and responsibilities), 'norming' (understanding and appreciating of each other's skills and abilities) before the group can begin to perform effectively (Tuckman, 1965). Davies (2009) mentions the "Ringelmann Effect" which shows that the larger the group the less individual members engage, cooperate and contribute to the group task. In the EAP classroom, group projects need to prepare students to 
interact effectively in larger mixed level groups for longer periods of time so students can experience forming, storming and norming.

In addition to the group project skills considered above, international students clearly need adequate language skills and familiarity with topic content, case study tasks, cultural understanding and familiarity with academic conventions of receiving department. The core academic competencies for this particular undergraduate group case study project are considered in terms of the four core language skills (See Fig. 2). In the discussion below, these are then compared to the BALEAP Can Do Framework of Competency Statements and overlap is highlighted.

Fig. 2.

Reading skills (BALEAP, 2015), for example, include the need to be able to read, at sufficient speed and depth, a variety of academic text formats critically, analytically and effectively including the project brief, the recommended websites, and additional literature as well as their own written work. In order to read the complex project brief and the recommended readings, international undergraduates would need to apply both cognitive and metacognitive reading skills as well as analysis, interpretation and inference. To fully understand the brief, they need to read, reread and mine for key information. The linguistic complexity also assumes sufficient linguistic competency to understand detailed instructions with modal verbs, complex sentence structures as well as general, AWL and discipline specific language. The lecturer emphasised that many 'flip through it' rather than reading it fully and carefully to identify the specific instructions and required components. In addition, international students often find western case studies demanding as they lack the regional and cultural background necessary for interpreting the information and are less used to dealing with the ambiguity or the open ended expectations of the approach (Jackson, 2003). As a result, some classroom tasks were extended to include more complex instructions with complex modal verb forms.

In order to read the two recommended web-based readings effectively, students would need to access and understand business reports. They need functional research skills to consult the table of contents; locate relevant sections; highlight key information; comprehend embedded subject specific language and pick apart the various complex diagrams, graphs and charts in the reports. They would also need to locate other relevant sources of information on green computing in books, academic articles and reports and select pertinent sections in order to synthesise a coherent product.

Effective speaking and discussion skills for engagement, interaction and negotiation were highlighted as crucial. The presentations can give international students an opportunity to present ideas and to persuade the audience of the innovation in their project. The discussion, on the other hand, requires students to speak spontaneously in order to build effective rapport and agreement, explain their own ideas and resolve misunderstandings and disputes (using strategic skills) which may arise with the exchange of diverse, unfamiliar ideas, opinions and suggestions. They also need to be able to challenge other participants or conventional ideas while listening actively and effectively. Academic 
discussion, according to Basturkmen (2002) is typically extended and more indirect and complex than previously identified. She notes that it goes beyond the initial elicitation, informational, or directive positions because speakers frequently provide further information, justification, or support for a point and often follow up over the course of several turns.

In the BALEAP speaking group competencies (BALEAP, 2015), there is considerable overlap as participating in group discussion, contributing to and engaging fully as well as analysing and solving problems and conveying thoughts or feelings are all mentioned. These speaking competencies also recognise that students need sophisticated presentation skills. In addition, under reading, the capacity to "analyse and discuss written text as group activity" (BALEAP, 2015, p. 17) is included.

In a multicultural context such as XX University's business school, international students also require intercultural communication skills for successful group interaction in this context. The skills are not entirely new to students who come with a certain level of communicative competence and an understanding of cultural contexts. The challenge that the students face is that of developing positive attitudes and strategies for cognitively and affectively managing the interaction between their old culture and the new culture. Intercultural competence does not entail replacing one culture with another but as noted by Kim (2001, p. 196), it is ..."'working through' of all cultural experiences, so as to create new constructs....". Intercultural communication skills are noticeably absent from the BALEAP Framework (BALEAP, 2015).

International students also need intercultural communication skills and time to adapt to their new multicultural environment. Adjusting behaviour to avoid fast judgements or stereotypical reactions as well as developing appropriate culture knowledge, effective communication skills, sensitivity and self awareness are all necessary for successful intercultural competence. The critical core skills for successful adaptation in these group interactions are motivation to communicate, appropriate culture knowledge, appropriate communication skills, sensitivity, and character according to Spencer-Oatey (2012). Students are expected to already possess some of these critical skills from their first language and cultures, but many find the transition challenging and worry about showing off, dominating, or making a mistake and losing face (Jackson, 2003). Such incidents need sensitive handling.

Gillett (2011, p. 4) notes that ..."EAP teaching is task based, using the types of academic task commonly found in higher education and writing classes are usually based on some kind of authentic extended writing task that the students do in their own time, with the help of in-class teaching, guided practice and individual tutorial support." However, this project demands collaborative writing and requires various discourse genres from minutes, study notes, a layman's exhibition guide and a web site, to an academic report with an executive summary and presentation slides. The group need to be able to paraphrase sources to avoid plagiarism, review their own written work critically and effectively and edit thoroughly to combine the various contributions as word limits are tight. The business lecturer explained that writing minutes proved to be especially demanding, despite the specific guidelines, as it forces groups to be autonomous and take responsibility. Many of these writing skills 
are BALEAP competencies but there is no mention of collaborative writing skills, which are core to this group project (BALEAP, 2015).

In addition, the lecturer stressed the importance of students being able to apply concepts by thinking critically and creatively, reflecting and accepting criticism. In addition, they needed to draw on past experience. This was highlighted as especially helpful when the students prepared work specifications and the interactive activities for the exhibition. Furthermore, opportunities for students to choose how to respond or be 'creative' proved to be particularly vague and difficult for international students and can be challenging for EAP practitioners too. Critical thinking skills, but not creativity, are included under BALEAP's writing and speaking competences, but the focus is towards individual interaction with a supervisor, rather than group interaction (BALEAP, 2015).

Finally, group assessment of peer performance was a controversial issue. In this project, students were required to agree on the allocation of marks providing evidence in the minutes, and, in some cases, to make a case for group members to receive unequal marks. Students who failed to attend meetings and participate were identified through the minutes and the group could then assign an unequal mark.

Passing responsibility to the group focuses students' attention on the need for collaboration and interdependence and so develops autonomy and responsibility. However, it is often considered unfair as it does not assess individual learning or contribution (Kagan, 1995) and may inflate marks (Davies, 2009). Ashraf (2004, p. 10) notes that "...Less Motivated students will get good grades at the expense of lower grades for Industrious students." This is a thought provoking issue for EAP practitioners to consider as it could disadvantage students from group oriented cultures who may prefer to maintain harmony. The need to "Engage in peer review" is briefly mentioned under BALEAP speaking competencies (BALEAP, 2015 p.10) but the focus is on detecting difficulties in engagement during group discussion, rather than negotiating for a particular mark. So in future group projects, these issues need to be taken into consideration.

A secondary goal for this in-house case study project was to prepare students for the real world of assessment centres where group tasks are used for business placements or internships. At an assessment centre, students are expected to be able to show a range of competencies including "team working skills; communication skills; leadership skills; time-management skills; listening skills; motivation and enthusiasm; data analysis skills; decision-making skills; influencing skills; creativity; integrity; and initiative" (Morton-Holmes, 2009, p.13). Just as the business lecturers develop in-house case studies, such as this one, to meet the needs of their new undergraduate students, EAP practitioners may need to create suitable pedagogical case studies from authentic cases, as purchased ones are often too long, too culturally specific or do not develop the transferable skills required for their future academic study. 


\section{Conclusion}

Group work projects come in all shapes and sizes. They can be short or long term and they can involve assigned or self-selected large or small groups of mixed international or home students. This group case study project investigation has revealed a chain of tasks requiring a range of skills that prove especially challenging for international students. The language demands include proficiently reading a long and complex brief; actively participating in group collaboration, process and procedures; searching, investigating and then applying research to the design of an exhibition site; finally, reporting the process in an assessed written report followed by an oral presentation.

Many of these competencies overlap with the BALEAP competency statements showing that first-year undergraduate students in this project are expected to achieve many of the competencies expected of masters' level students. However, intercultural communication skills, collaborative writing skills or group assessment of peer performance are not mentioned. Additionally, learner factors, including personal affective response (e.g. confidence and motivation); and other skills including time management; IT skills; application of concepts and group dynamics are highlighted in this project.

A number of generic insights from the study can be transferred to EAP presessional or foundation programmes despite the fact that the study is limited by the fact that insights into task demand were only gathered from the senior business lecturer and marking notes. Further information could be gathered by surveying students to gather their perspectives on the group experience and project for dissemination. It is increasingly important for EAP programmes to be more informed about the types of group projects used within receiving departments and for practitioners to utilise more demanding chains of tasks and assess them using a task-based framework. In addition, they should explore the related academic literacy expectations of authentic real world case studies and collaboratively written reports. Most pedagogic EAP group projects are short term and although they can involve assigned or self-selected groups, most tend to use small rather than large groups and multicultural rather than same nationality or mixed international and home students. More could be designed to include functional language for interactional competence that goes beyond turn-taking, agreeing and disagreeing or to incorporate collaborative writing of minutes, reports or executive summaries. A student centred learning focus which develops language skills, discipline content familiarity, learner autonomy, responsibility, initiative and reflection could also be developed in a supportive environment with students being encouraged to seek advice and support as required. This information could then be shared through faculty liaison with subject lecturers.

It is suggested that EAP pedagogic group projects for business and management, and possibly for other departments such as engineering or education which frequently use group projects (Thondhlana \& Smith, 2013), be designed to consist of chains of tasks which build towards the final assessments. Project documents should, in some cases, use complicated extended formats with complex language for the group task instructions so they can be unpacked in class. The projects need to ensure opportunities for negotiation, problem solving, decision making and evaluation within the group 
discussions so cross cultural communication issues that surface can be explored and resolved with consultation. In addition, collaborative writing assessments can be considered that require teamwork and critical thinking.

\section{References}

Ashraf, M. (2004). A critical look at the use of group projects as a pedagogical tool. Journal of Education for Business, 79(4), 213-7.

BALEAP (2015). Can Do Framework: Competency statements for international students (Master's level). Available at http://www.baleap.org.uk/projects/can-do-working-party Accessed 2 February 2015.

Basturkmen, H. (2002). Negotiating meaning in seminar-type discussion and EAP. English for Specific Purposes, 21, 233-242.

Basturkmen, H. (2006). Ideas and options in English for specific purposes. London: Routledge.

Brindley, G. (1987). Factors affecting task difficulty. In D. Nunan (Ed.), Guidelines for the development of curriculum resources (pp. 45-56). Adelaide: National Curriculum Resource Centre.

Bygate, M., Skehan, P., and Swain, M. (Eds.) (2001). Researching pedagogic tasks: second language learning, teaching and testing. Harlow: Pearson Education.

Canale, M., and Swain, M. (1980). Theoretical bases of communicative approaches to second language teaching and testing. Applied Linguistics, 1, 1-47.

Candlin, C. (1987). Towards task-based learning. In C. N. Candlin and D. Murphy (Eds), Language learning tasks (pp. 5-22). Englewood Cliffs, NJ: Prentice-Hall International.

Celce-Murcia, M., Dörnyei, Z., and Thurrell, S. (1995). Communicative competence: A pedagogically motivated model with content specifications. Issues in Applied Linguistics, 6(2), 5-35. University of California: Regents.

Chapman, K.J., Meuter, M., Toy, D., and Wright, L. (2006). Can't we pick our own groups? The influence of group selection method on group dynamics and outcomes. Journal of Management Education, 30(4), 557-569.

Chen, G., and Starosta, W. (1998). A review of the concept of intercultural sensitivity. Human Communication, 1, 1-16.

Child, D. (2010). Readability-score.com GitHub Inc. Available at https://readability-score.com/ Accessed 3 November, 2014.

Cobb, T. (n.d.). Compleat lexical tutor. University of Quebec, Montreal. Available at www.lextutor.ca/ Accessed 3 November, 2014.

Colbeck, C., Campbell, S., and Bjorklund, S.A. (2000). Grouping in the dark: What college students learn from group projects. Journal of Higher Education, 71(1), 60-83.

Coxhead, A., and Nation, P. (2001). The specialised vocabulary of English for academic purposes. In J. Flowerdew and M. Peacock (Eds.), Research perspectives on English for academic purposes. (pp. 252-267). Cambridge: Cambridge University Press. 
Crookes, G. (1986). Task classification: A cross-disciplinary review. Technical Report no. 4, The Center for Second Language Classroom Research, Social Science Research Institute: University of Hawai'i at Manoa.

Crossley, S., Greenfield J., and McNamara, D.S. (2008). Assessing text readability using cognitively based indices. TESOL Quarterly 42(3), 475-493.

Davies, M. (2009). Group work as a form of assessment: common problems and recommended solutions. Higher Education, 58, 563-584.

Dudley-Evans, T., and St. John, M. (1998). Developments in ESP: A multi-disciplinary approach. Cambridge: Cambridge University Press.

Duff, P. (1986). Another look at interlanguage task: Taking task to task. In R. Day (Ed.), Talking to Learn. (pp. 147-181). Rowley, MA: Newbury House.

Ede, L., and Lunsford, A. (1990). Singular Texts/Plural Authors: Perspectives on Collaborative Writing, Carbondale, IL: Southern Illinois University Press.

Ellis, R. (2003). Task-based language learning and teaching. Oxford: Oxford University Press.

Ellis, R. (2006). The Methodology of task-based teaching. Asian EFL Journal, 8(3), 19-45.

Evans, S., and Morrison, B. (2011). Meeting the challenges of English-medium higher education: The first year experience in Hong Kong. English for Specific Purposes, 30, 198-208.

Finkbeiner, C. (2008). Culture and good language learners. In C. Griffiths (Ed.), Lessons from good language learners (pp. 35-48). Cambridge: Cambridge University Press.

Flowerdew, J., and Peacock, M. (2001). Research perspectives on English for academic purposes. Cambridge, Cambridge University Press.

Foster, P., and Skehan, P. (1996). The influence of planning and task type on second language performance. Studies in SLA, 9, 12-20.

Garcia-Mayo, M. (2007). Investigating tasks in formal second language learning. Clevedon UK: Multilingual Matters.

Gillett, A. (2011). What is EAP? Available at http://www.uefap.com/bgnd/ Accessed 3 November, 2014.

Hunt, K. (1970). Syntactic maturity in school children and adults. Monographs of the Society for Research in Child Development, 35, iii-iv, 1-67.

Hyland, K. (2002). Specificity revisited: how far should we go now? English for Specific Purposes, 1 , $1-12$.

Hyland, K. (2006). English for academic purposes: an advanced resource book. Abington, UK.: Routledge.

Hyland, K. (2008). Disciplinary voices: Interactions in research writing. English Text Construction 1 (1), 5-22.

Johns, T. (1988). 'Whence and whither classroom concordancing?' In: P. Bongaerts, P. de Haan, S. Lobbe and H. Wekker (Eds.), Computer Applications in Language Learning (pp. 9-27). Dordrecht: Foris.

Hyland, K., and Hamp-Lyons, L. (2002). EAP: Issues and directions. Journal of English for Academic Purposes, 1, 1-12. 
Hansen, R. (2006). Benefits and problems with student teams: Suggestions for Improving team projects. Journal of Education for Business, 82 (1), 11-19.

Hunt, K. (1970). Syntactic maturity in school children and adults. Monographs for the society for research in child development, 35(134).

Jackson, J. (2003). Case-based learning and reticence in a bilingual context: perceptions of business students in Hong Kong. System, 31, 457-469.

Jackson, J. (2002). The China Strategy: A tale of two case leaders. ESP Journal, 21(3), 243-259.

Kagan, S. (1995). Group grades miss the mark. Educational Leadership, 52(8), 68-71.

Kim, Y. (2001). Becoming Intercultural: An Integrative Theory of Communication and Cross-Cultural Adaptation. Thousand Oaks, CA: Sage.

Leki, I. (2007). Undergraduates in a second language. New York: Lawrence Erlbaum Associates.

Long, M. (1989). Task, group, and task-group interactions. University of Hawaii Working Papers in ESL, 8, 1-26.

Long, M., and Crookes, G. (1992). Three approaches to task based syllabus design. TESOL Quarterly, 26(1), 27-55.

Lowry, P., Curtis, A., and Lowry, M. (2004). Building a taxonomy and nomenclature of collaborative writing to improve interdisciplinary research and practice. Journal of Business Communication, 41(1), 66-99.

Mohan, B., and Smith, S. (1992). Context and action in academic tasks. In D. Nunan (Ed.), Collaborative language learning and teaching. (pp. 81-99). Cambridge: Cambridge University Press.

Morton-Holmes, I. (2009). Going for Interviews. UK. :Robert Gordon University. Available at http://www4.rgu.ac.uk/files/Going\%2520for\%2520interviews.pdf Accessed 4 February, 2015.

Nation, P., and Waring, R. (1997). Vocabulary size, text coverage, and word lists. In Schmitt, N., and McCarthy, M. (Eds.) Vocabulary: Description, acquisition, pedagogy. (pp. 6-19). New York: Cambridge University Press. Available at http://www.lextutor.ca/research/nation_waring_97.html Accessed 3 November, 2014.

Nunan, D. (1991). Communicative tasks and the language curriculum. TESOL Quarterly, 25(2) 279293.

Pica, T., and Doughty, C. (1985). Input and interaction in the communicative language classroom: a comparison of teacher-fronted and group activities. In S. M. Gass and C. G. Madden (Eds.), Input in second language acquisition (pp. 115-132). Rowley, MA: Newbury House.

Prabhu, N. (1987). Second language pedagogy. Oxford: Oxford University Press.

Robinson, P. (2001). Task complexity, task difficulty, and task productions: exploring interactions in a componential framework. Applied Linguistics, 22, 27-57.

Robinson, P., Ting, C., and Urwin, J. (1996). Investigating second language task complexity. RELC Journal, 2, 62-79.

Robinson, P. (2006). Criteria for classifying and sequencing pedagogic tasks. In M. P. Garcia-Mayo (Ed.), Investigating tasks in formal language learning (pp. 7-26). Clevedon, UK: Multilingual Matters.

School of Business. (2009). Undergraduate Student Handbook. University of xxxx. 
Summers, M., and Volet, S. (2008). Students' attitudes towards culturally mixed groups on internationals campuses: impact on participation in diverse and non-diverse groups. Studies in Higher Education, 33(4), 357-370.

Shepperd, M. (2011). Group project work from the outset: An in-depth teaching experience report. 24th IEEE Conference on Software Engineering Education and Training, Honolulu, May 2011, IEEEXplore 361-370. Available at http://bura.brunel.ac.uk/handle/2438/5005 Accessed 3 November, 2014.

Skehan, P. (1998). A cognitive approach to language learning. Oxford: Oxford University Press.

Skehan, P., and Foster, P. (1997). Task type and task processing conditions as influences on foreign language performance. Language Teaching Research, 1(3), 185-211.

Smith, A. F. V. (2009). A case for discussion. In A. F. V. Smith, \& G. Strong (Eds.), Adult language learners: Context and innovation, TESOL Classroom Practice Series. USA: TESOL.

Spencer-Oatey, H. (2012). Competency framework for effective intercultural interaction. UK: University of Warwick.

Thondhlana, J., \& Gao, X. (2009). Needs analysis project: Phase I report. University of Nottingham. Thondhlana, J., \& Smith, A. (2013). Cracking the case: a task based investigation of a business case study group project. Journal of Business and Technical Communication, 27(1), 32e61.

Tuckman, B. (1965). Developmental sequence in small groups. Psychological Bulletin, 63, 384-399. Van den Branden, K. (2006). Task-based language education: from theory to practice. Cambridge: Cambridge Applied Linguistics.

Victoria University of Wellington, UTDC. (2004). Group work and group assessment. Victoria University of Wellington. Available at http://www.victoria.ac.nz/vbs/teaching/steps-to-teachingsuccess/group-work Accessed 3 November, 2014.

Watson Todd, R. (2003). EAP or TEAP? Journal of English for Academic Purposes, 2, 147-156. Willis, D., and Willis, J. (2007). Doing task-based teaching. Oxford: Oxford University Press. Young. R. F. (2011). Interactional competence in language learning, teaching, and testing. In E. Hinkel (Ed.), Handbook of research in second language teaching and learning, 2 (pp. 426-443). London and New York: Routledge.

Appendix

The AWL items are highlighted in bold in the following document example from Part 1: "This assignment is intended to test a range of participant competencies in the area of information and communications technology (ICT) specification, budgeting and strategy formulation, in addition to group working, collaborative document preparation and presentation skills." 